\title{
The Study of Training Needs Assessment of Subject Matter Specialists of the KVKS of the State of Manipur, India
}

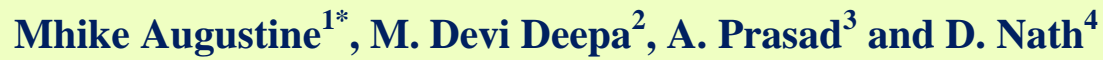 \\ College of Agriculture, Central Agricultural University, Imphal, Manipur, India \\ *Corresponding author
}

\section{A B S T R A C T}

\section{Keywords}

Subject Matter Specialists, KVKs, Agricultural Economics

Article Info

Accepted:

28 July 2020

Available Online:

10 August 2020
In study on training needs of SMSs of KVKs of the State of Manipur, the following was observed, personal and psychological characteristics of the SMSs; on "Age", the Middle Age portrayed the highest per cent (75.60\%), followed by the Young Age with 15.50 per cent and lastly, the Old Age with the lowest per cent (8.90\%).For the "Educational level", M.Sc. (Ag.) level constituted 53.30 per cent followed by 44.40 per cent Ph.D. degree level and no PGDC holders. For the "Training exposure" the highest was the medium level with 82.22 per cent, on "Service experience" the highest per cent was in the medium level with 64.50 per cent. For "Attitude towards agriculture profession", the attitude was favourable with 95.60 per cent. Job satisfaction was assessed and the maximum per cent was under satisfied $(91.20 \%)$. For Information seeking behaviour, the maximum respondents $(57.80 \%)$ fell under medium category. For Information sharing behaviour, the medium category was the highest $(57.80 \%)$ and lastly for "training needs" most SMSs were in the medium category $(73.40 \%)$. From the data collected the overall training needs score (OTNS) was calculated. It was found that the most important training need in Soil Science was "Soil conservation and its importance"; in Horticulture, "Methods of fruit and vegetable preservation"; in Agronomy, "Crop rotation and its importance"; in Plant Pathology, "Methods of application of chemicals, preparation and dozes"; in Nematology, "Nematodes pest control in vegetables"; in Agricultural Extension, "Promotion of rural youth activities", and in Agricultural Economics, "Marketing of agricultural produce". To determine the relationship between the independent variables and the dependent variable, Spearman's rank correlation analysis technique was used. "Attitude towards agriculture profession" was found to be positively correlated with the training needs $(0.417 * *)$ at 0.01 per cent level of significance and "Training exposure", was found to be negatively correlated with the training needs $(-0.303 *)$ at 0.05 per cent significance. The following independent variables were found to be having insignificant relationship with the training needs; "Age", "Educational level", "Service experience", "Job satisfaction", "Information seeking behaviour", and "Information sharing behaviour."

\section{Introduction}

\section{Agriculture scenario}

The world's population is increasing tremendously and India is no exception. India has to feed a population of 1.21 billion and export excess food to improve its National Gross Domestic Product. (Anon., 2015-16).

Agriculture is the backbone of India's economy. If India has to experience growth and development of its economy, it is imperative to focus more on ensuring food 
and nutrition security and eliminate poverty among the rural communities. The economic growth can only be achieved when agriculture production is improved. (Anon., 2015-16). Adopting new agricultural technology is critical in improving agricultural productivity.

The major impediment to agricultural production lies sincerely on current traditional food production practices, where farmers are more comfortable in using their traditional tools and seed. They use tools that can manage to work smaller land units per given year and seed that yield far less than hybrid varieties.

On the other hand, the farmers are experiencing severe climate change and climate variability effects in the form of increase in temperature, reduced monsoon rainfall and outbreaks of unfamiliar pests, affecting mainly their rabi crop, (Anon., 2014). A vibrant agriculture extension system backed by effective technological demonstrations at the farmer's backyard can solve some of these challenges.

Climate challenges can be averted by adopting acceptable new agricultural technologies. High agriculture productivity can be achieved at farm level through the use of high yielding seed varieties, drought tolerant cereals, grains and breeding of livestock tolerant to changing environmental conditions.

New agricultural technologies have been invented by agricultural universities and various research institutes to improve efficiency in the production of food crops and livestock for food. However, if these technologies are not exposed to farmers to use at farm level, productivity will remain constrained. Farmers can adopt these technologies if they are exposed to them through training. Linking them to $\mathrm{KVK}$
Subject Matter Specialists training activities, we envisage developed new agricultural technologies being accepted and intensively used by the practising farmers. Some traditional technologies are generally a drawback to productivity and youth employment in agriculture due to high drudgery.

Therefore, the Krishi Vigyan Kendras through their Subject Matter Specialists should create hope of modernizing agriculture production systems for national food and nutrition security.

In India, a total of $716 \mathrm{KVKs}$ are in operation as centres of farming excellence. In the State of Manipur, there are nine KVKs. KVKs are the key driver of scientific agricultural knowledge within the districts they are operating and through them, agricultural development is envisaged in India. Over the years, the KVK's main mandate has evolved to cover the following areas: organize Frontline Demonstrations to establish production potential of technologies on the farmers' fields, capacity development of farmers and extension personnel to update their knowledge and skills on modern agricultural technologies, work as knowledge and resource centre of agricultural technologies for supporting initiatives of public, private and voluntary sector in improving the agricultural economy of the district, provide farm advisories using ICT and other media means on varied subjects of farmer's interest, vocational training programs for farmers, farm women, rural youth, and extension functionaries and provision of making available the quality seed and other planting materials to farmers.

The Subject Matter Specialists of the KVKs are a hub of transfer of current agriculture knowledge systems and because they have specialized in different disciplines of 
agriculture. Agricultural entrepreneurs and practising extension functionaries are trained to bridge the agricultural knowledge gap to improve agricultural production in the State.

\section{Training and its importance}

Training is critical in human resources development for employees to carry out their duties effectively and efficiently. Employees must have relevant skills, knowledge, attitudes and competences for the organisation to perform its intended mandate. Also the (United Nation's Development Programme, 2001) supports this notion that, human resources development encompasses two aspects; formation of human capabilities such as improved health, knowledge and skills and the use of acquired capabilities for the productive purposes.

Therefore with this in mind, training remains a paramount process of imparting specific skills to perform activities in a better and more informed way. Newly employed personnel will acquire competences required for their jobs by undergoing various training programmes.

Beardwell and Holden (1998) also reaffirm the following as reasons for training and development of employees in organisations: that new employees are like raw material, they need to be processed so that they are able to perform the tasks of the jobs adequately and fit into work groups and organisation. Employees change their interest, their skills, their confidence and aspirations with changing circumstances.

The organisation may wish to prepare for future changes and require some employees to develop transferable skills. So in this context, employees have to be updated through training. Training is therefore, an essential component for organisations that are very serious about being leaders in their trade (Beardwell and Holden, 1998).

Robbins and Judge (2007) also relate the same that employees do not remain competent forever. There is skills deterioration, obsolesce and therefore, new skills need to be imparted through training. Training is directed at improving and upgrading employee's technical skills.

Training has become increasingly important for two main reasons in organisations: for employees to acquaint themselves well to new technology, new organisational structure design and due to changes in jobs and duties.

In this regard, SMSs should manage to impart skills to the farming community on the challenges they are facing. KVKs operations therefore become critical in agriculture knowledge diffusion and promotion of productivity at farm level. The complexity of agricultural technology calls upon SMSs to be more proactive in imparting proper attitudes, knowledge and skills to the practising farmers and extension functionaries to develop agriculture.

SMSs duties are related to transfer and transformation of technology to a localized setting. It is therefore critical for the SMS to be highly competent. The workplace environment demands major changes in formal education and concentrates on professional training. SMSs regardless of their high educational qualifications they still require training in a number of emerging issues to answer the demands of their current job without a challenge.

Training needs assessment provides a strategic guideline as to which professional deficiencies the SMSs may expose during the performance of their jobs. New SMSs at the work place need to be inducted into the 
operation of KVKs so that they become aware of the organisational culture and their roles in the organisations.

Educating a person is to make him to be fit, qualified and proficient in doing some job. It reduces the obsolescence among the workforce in relation to technological innovation (Dahama and Bhatnagar, 1980).

Basically, training should be need based and therefore it is imperative to conduct training needs assessment to identify staff training needs so that the management can efficiently plan for training. Training needs of SMSs change with time and changing trends of agriculture. Hence, the emphasis is to carry out the training needs assessment regularly.

Through training, agricultural technologies can be transferred to the farmers. The question is, "whether the farmers are getting the information that they require and use these agricultural technologies to their advantage?"

Keeping this in mind, the competent and well trained SMSs of KVKs will be capable to pass on the knowledge to the farmers and extension functionaries for technology adoption and use.

Success of KVK operations can only be realized when skills, attitudes and vast knowledge in agriculture are imparted to SMSs and passed on to the extension functionaries and farmers.

\section{Materials and Methods}

A study on the training needs assessment of the SMSs was done from a total of nine KVKs of the State of Manipur which were the researcher's universe. The nine KVKs are under different administrative units, viz; State Department of Agriculture total number (1); Central Agricultural University (1); Indian
Council of Agricultural Research (5) and Non-Governmental Organisation (2). A census method was used in the collection of data from the 45 Subject Matter Specialists with the aid of a well-structured schedule. Some required information was also collected through interviewing the respondents by the researcher. Descriptive and inferential statistics was used to analyse the data. The information collected was in relation to the personal and socio-psychological characteristics of the respondents and the following independent variables were used for the study (Age, Educational level, Training exposure, Service experience, Attitude towards agriculture profession, Job satisfaction, Information seeking behaviour and Information sharing behaviour).The hypothesis of the study, denoted by $\mathrm{H}_{0}$ was formulated stating that there will be significant relationship between the training need of the respondents and the following variables Age, Educational level, Training exposure, Service experience, Attitude towards agricultural profession, Job satisfaction, Information seeking behaviour and Information sharing behaviour relationship between the respondents' training needs and the independent variables stated earlier on. The respondents completed the schedules expressing their perception on the variables using provided means of measurements. Frequencies and percentages were calculated about their Ages, Educational levels etc. Their training needs from the subjects area components were also calculated using the following formula:

\section{OTNS $=\frac{\text { Maximum score obtained }}{\text { Maximum possible score }} \times 100$}

Where OTNS means overall training needs score

The relationship of the socio-psychological characteristics and training need areas of the respondents were determined using a 
statistical tool called the Spearman rank correlation. The Spearman's rank correlation coefficient is denoted by $\mathrm{r}$ - value which lies between -1 and +1 . An $\mathrm{r}_{\mathrm{s}}, R$ or $\rho$ of +1 indicates perfect positive association of ranks. An $\mathrm{r}_{\mathrm{s}}, R$ or $\rho$ of zero indicates no association between the ranks and $\mathrm{r}_{\mathrm{s}} R$ or $\rho$ of -1 indicates perfect negative association of the ranks. The closer the $\mathrm{r}_{\mathrm{s}}, R$ or $\rho$ is to zero the weaker the association between ranks.

\section{Results and Discussion}

\section{Age}

The table 1 depicts that 15.50 per cent of the respondents belonged to the Young age (Up to 35 years). Middle age (36-55 years) had 75.60 per cent and 8.90 per cent is from the Old age (56 years and above). The mean and standard deviation were calculated as 42.71 and 7.82 respectively.

\section{Educational level}

The table 2 reflects that 2.22 per cent of the respondents were B.Sc. (Agri.) degree holders followed by 53.33 per cent M.Sc. (Agril.) degree holders, zero per cent from the PGDC and 44.45 per cent had $\mathrm{PhD}$ degree level of education.

\section{Training exposure}

The table 3 depicts that the training exposure of 6.67.per cent of the respondents was low, 82.22 per cent of respondents were in medium level category and 11.11 per cent of the respondents were in the high level category of training exposure. The mean and standard deviation were 6.60 and 5.90 respectively.

\section{Service experience}

The table 4 shows that 22.20 per cent of respondents were in the category of (Up to 8) years' while 64.50.per cent had 9-17 years' service experience and 13.30 per cent of the respondents had more than 18 years' service experience. The mean and standard deviation were 12.76 and 7.17 respectively.

\section{Attitude towards Agriculture Profession}

The table 5 shows that 95.60 per cent of the respondents were discovered to be in the favourable category and 4.40 per cent of the respondents were found to have an unfavourable attitude towards the agriculture profession. The mean and standard deviation were 12.76 and 8.98 respectively.

\section{Job Satisfaction}

The table 6 depicts that 91.20 per cent of respondents were satisfied with their jobs, followed by 4.40 per cent of respondents who were highly satisfied category with their job and 4.40 per cent of the respondents were in the highly unsatisfied with their jobs. The mean and standard deviation were 126.77 and 17.54 respectively.

\section{Information seeking behaviour}

Table 7 showed that the information seeking behavior of 15.50 per cent of the respondents was in the low level category, 57.80 per cent were in the medium category and 26.70 per cent of respondents had a high level category of the information seeking behaviour. The mean was 25.35 and standard deviation was 6.04 respectively.

\section{Information sharing behavior}

The table 8 shows that 2.20 per cent of the respondents were in the low level category of information sharing behaviour, 57.80 per cent were in the medium level category of information sharing behaviour and 40.00 per cent were in the high level of information sharing behaviour. 
Training needs areas of the respondents in different agriculture disciplines

The following were the identified priority areas in the stated agriculture disciplines: In Soil Science ten (10)perceived training needs were assessed and it was observed that respondents mostly needed training were in the following order: "Soil conservation and its importance," with a score of 2.62, and followed by, "Green manure and compost making", with a 2.51 score and lastly "Biofertilizers, its importance and use", with score of 2.44 .

In Agronomy assessment was done using seventeen (17) perceived training needs. The results showed that, "Crop rotation and its importance", with a score of 2.64 was the most needed, followed by, "Knowledge of important crop varieties for Manipur", with a score of 2.44.It was also followed by a tie of, "Cropping systems" with score of 2.42 and "Storage of grain", with also a score of 2.42.The $4^{\text {th }}$ also was a tie with the following, "Sources of good seed," with score of 2.36 and "Seed storage", with a score of 2.36as well.

In Horticulture assessment was done using twelve (12) perceived training needs and was reflected that "Methods of fruit and vegetable preservation including indigenous methods", with a score of 2.31 was the most needed and the $2^{\text {nd }}$ being, "Art of pruning, grafting and stalking", with a score of 2.27 and the $3^{\text {rd }}$, "Production technology of winter vegetables", with a score of 2.24 and lastly "Different equipment for pruning, grafting and spraying etc.", with a score of 2.18 .

In Entomology assessment was done using seventeen (17)perceived training needs, it was observed that respondents mostly needed training in, "Diagnostics and characteristic, symptoms and damage caused by insect pests", with score of 2.51 tied with "Symptoms, spread and control of important insect pests in rice", 2.51.This was followed with another tie of; "Insect pest management and its components(cultural, mechanical, biological, chemical and legal)",and "Identification of different pests and pesticides", both with scores of 2.49 .

In Plant Pathology assessment was done using sixteen(16) perceived training needs, it was observed that the respondents mostly needed training in; "Methods of application of chemicals, preparation and doses" with a score of 2.51, followed by, "Study of causes, symptoms, spread and control of important diseases in rice", with a score of 2.49 and the $3^{\text {rd }}$ was, "Study of the causes, symptoms, spread and control of important diseases in vegetables", with a score of 2.40 .

In Nematology assessment was done using eight (8) perceived training needs and it showed that respondents most needed training in; "Nematode pest control in vegetables", with a score of 2.38 , the $2^{\text {nd }}$ was, "Nematode pest control in pulses", with score of 2.29, and the $3^{\text {rd }}$ was, "Nematode pest control in cereals", with a score of 2.28 and lastly, "Important nematicide used in different crops", with a score of 2.27 .

In Agriculture Extension assessment was done using twenty-two (22) perceived training needs and it was revealed that respondents mostly needed training in "Promotion of rural youth activities", with a score of 2.60 , the $2^{\text {nd }}$ was, "Organisation of farm and farm women for agricultural production programmes," with a score of 2.58 and lastly the $4^{\text {th }}$ was, "Extension Programme Planning and Monitoring at village level", with a score of 2.56 .

In Agricultural Economics assessment was done using seven(7) perceived training needs 
which showed that respondents mostly needed training was, "Marketing of Agricultural products", with score of 2.58 , the $2^{\text {nd }}$ was, "Sources of loan, knowledge of different credit institutions/agents" with a score of 2.49 , the $3^{\text {rd }}$ was "Farm management and economic production", with a score of 2.40 . "Seed production techniques" and "Drudgery reduction techniques", were also noted with scores of 2.33 and 2.24 respectively.

\section{Training needs scores}

The table 9 depicts that 73.40 per cent of the respondents showed medium level of training needs, followed by 13.30 per cent of the respondents in the low level of the training needs and lastly 13.30 per cent again were in the high level of training needs. Mean and standard deviation were 76.67 and 13.57 respectfully.

Table 10 shows that the independent variable of Attitude towards Agricultural Profession was positively correlated with training needs at $\left(0.417^{* *}\right) \quad 0.01$ per cent level of significance. The hypothesis that there is a significant relationship with the training needs was accepted. Similar findings were also noted by Deena, et al., (2019) Training exposure showed a negative correlation relationship with the training needs at ($0.303 *) 0.05$ per cent level of significance. The hypothesis that there was a significant relationship with the training needs was accepted. Similar findings were also noted by other researchers (Lego, 1995; Kshash, 2012 and Norsida, et al., 2016).

The Age of the respondents was found to have no significant relation with the training needs. The hypothesis that there is a significant relationship between Age of the respondents and the training needs was rejected. Similar findings were also noted by Nanda, et al., (1994).
Educational level of the respondents was found to have no relationship with the training needs. The hypothesis that there is significant relationship between education level and the training needs was also rejected. Similar findings were also noted by other researchers (Nanda, et al., 1994 and Yadav, et al., 2013).

Service experience of the respondents was found to have no relationship with the training needs. The hypothesis that there is significant relationship between the service experience and the training needs was rejected. Similar findings were also noted by Yadav, et al., (2013).

Job satisfaction of the SMSs was found to have no relationship with the training needs. The hypothesis that there is significant relationship between job satisfaction and the training needs was rejected.

Information seeking behaviour of the respondents was found to have no relationship with training needs. The hypothesis that there is significant relationship between information seeking behaviour with the training needs was rejected.

Information sharing behaviour of the respondents was found to have no relationship with the training needs. The hypothesis that there is a significant relationship between information sharing behaviour and the training needs was rejected.

The research also discovered that majority $(73.40 \%)$ of the respondents' training needs were in the medium level. Training needs areas of the respondents in different agriculture disciplines

The following were the identified priority areas in the stated agriculture disciplines: In Soil Science ten (10) perceived training needs were assessed and it was observed that 
respondents mostly needed training were in the following order: "Soil conservation and its importance," with a score of 2.62, and followed by, "Green manure and compost making", with a 2.51 score and lastly "Biofertilizers, its importance and use", with score of 2.44 .

In Agronomy assessment was done using seventeen (17) perceived training needs. The results showed that, "Crop rotation and its importance", with a score of 2.64 was the most needed, followed by, "Knowledge of important crop varieties for Manipur", with a score of 2.44.It was also followed by a tie of, "Cropping systems" with score of 2.42 and "Storage of grain", with also a score of 2.42.The 4th also was a tie with the following, "Sources of good seed," with score of 2.36 and "Seed storage", with a score of 2.36 as well.

Table.1 Distribution of respondents according to Age $n=45$

\begin{tabular}{|l|l|l|c|c|}
\hline SI. No. & Category & Age range & Frequency & \% distribution \\
\hline 1. & Young Age & Up to 35 years & 07 & 15.50 \\
\hline 2. & Middle Age & 36 to 55 years & 34 & 75.60 \\
\hline 3. & Old Age & 56 years and above & 04 & 8.90 \\
\hline TOTAL & & & $\mathbf{4 5}$ & $\mathbf{1 0 0 . 0 0}$ \\
\hline \multicolumn{2}{l}{ Mean $=\mathbf{4 2 . 7 1}$} & & & S.D $=\mathbf{7 . 8 2}$ \\
\hline
\end{tabular}

Table.2 Distribution of respondents according to Educational level $n=45$

\begin{tabular}{|l|l|c|c|}
\hline SI. No. & Category & Frequency of SMSs & \% Distribution of SMSs \\
\hline 1. & B.Sc. (Ag.) & 01 & 02.22 \\
\hline 2. & M.Sc. (Ag.) & 24 & 53.33 \\
\hline 3. & PGDC & 00 & 00.00 \\
\hline 4. & Ph.D. & 20 & 44.45 \\
\hline TOTAL & $\mathbf{4 5}$ & $\mathbf{1 0 0 . 0 0}$ \\
\hline
\end{tabular}

Table.3 Distribution of respondents according to Training Exposure $n=45$

\begin{tabular}{|l|l|c|c|c|}
\hline SI. No. & Category & Score & Frequency & \% Distribution \\
\hline 1. & Low $($ Up to Mean-S.D ) & $0-0.60$ & 03 & 06.67 \\
\hline 2. & Medium (Mean \pm S.D) & $0.61-12.59$ & 37 & 82.22 \\
\hline 3. & High (Mean + S.D) & $12.60+$ & 05 & 11.11 \\
\hline & TOTAL & & $\mathbf{4 5}$ & $\mathbf{1 0 0 . 0 0}$ \\
\hline
\end{tabular}

Table.4 Distribution of respondents according to Service Experience $n=45$

\begin{tabular}{|l|l|l|c|c|}
\hline SI. No. & Category & Score & Frequency & \% Distribution \\
\hline $\mathbf{1}$ & Low (Up to Mean - S.D) & (Up to 8) years & 10 & 22.20 \\
\hline $\mathbf{2}$ & Medium (Mean \pm S.D) & (9-17) years & 29 & 64.50 \\
\hline $\mathbf{3}$ & High $($ Mean + S.D) & 18 years+ & 06 & 13.30 \\
\hline TOTAL & & & $\mathbf{4 5}$ & $\mathbf{1 0 0 . 0}$ \\
\hline
\end{tabular}


Table.5 Distribution of respondents according to Attitude towards Agricultural Profession $\mathrm{n}=45$

\begin{tabular}{|l|l|l|c|c|}
\hline SI. No. & Category & Score & Frequency & \% Distribution \\
\hline 1. & Favourable & Above 60 & 43 & 95.60 \\
\hline 2. & Unfavourable & Below 60 & 02 & 04.40 \\
\hline TOTAL & & & $\mathbf{4 5 . 0 0}$ & $\mathbf{1 0 0 . 0 0}$ \\
\hline
\end{tabular}

Table.6 Distribution of respondents according to Job Satisfaction $n=45$

\begin{tabular}{|l|l|l|c|c|}
\hline SI. No. & Category & Score & Frequency & \%Distribution \\
\hline 1. & Highly Unsatisfied (Up to Mean-S.D) & $0-95$ & 02 & 04.40 \\
\hline 2. & Satisfied (Mean + S.D) & $96-146$ & 41 & 91.20 \\
\hline 3. & Highly Satisfied (Mean + S.D) & $147-176$ & 02 & 04.40 \\
\hline Total & & & $\mathbf{4 5}$ & $\mathbf{1 0 0 . 0 0}$ \\
\hline
\end{tabular}

Table 7 Distribution of respondents according to Information Seeking Behaviour $n=45$

\begin{tabular}{|l|l|l|c|c|}
\hline SI. No. & Category & Score & Frequency & \% Distribution \\
\hline 1. & Low $($ Up to Mean - S.D) & $0-19$ & 07 & 15.50 \\
\hline 2. & Medium $($ Mean \pm S.D) & $20-31$ & 26 & 57.80 \\
\hline 3. & High $($ Mean + S.D) & $32-34$ & 12 & 26.70 \\
\hline Total & & & $\mathbf{4 5}$ & $\mathbf{1 0 0 . 0 0}$ \\
\hline
\end{tabular}

Table.8 Distribution of respondents according to Information Sharing Behaviour $n=45$

\begin{tabular}{|l|l|l|c|c|}
\hline SI. No. & Category & Score & Frequency & \% Distribution \\
\hline 1. & Low (Up to Mean-S.D) & $0-11$ & 01 & 02.20 \\
\hline 2. & Medium (Mean + S.D) & $12-22$ & 26 & 57.80 \\
\hline 3. & High (Mean + S.D) & $23-28$ & 18 & 40.00 \\
\hline Total & & & $\mathbf{4 5}$ & $\mathbf{1 0 0 . 0 0}$ \\
\hline
\end{tabular}

Table.9 Distribution of respondents according to Training needs score $n=45$

\begin{tabular}{|l|l|l|c|c|}
\hline SI. No. & Category & Score & Frequency & \% Distribution \\
\hline 1. & Low (Up to Mean-S.D) & $0-63.10$ & 06 & 13.30 \\
\hline 2. & Medium (Mean \pm S.D) & $63.11-90.25$ & 33 & 73.40 \\
\hline 3. & High (Mean + S.D) & $90.26-100$ & 06 & 13.30 \\
\hline TOTAL & & $\mathbf{4 5}$ & $\mathbf{1 0 0 . 0 0}$ \\
\hline
\end{tabular}


Table.10 Spearman's rank correlation of the training needs and personal, socio-psychological characteristics of the respondents $n=45$

\begin{tabular}{|l|l|l|}
\hline SI. No. & Independent variables & r-values \\
\hline $\mathbf{1 .}$ & Age $\left(\mathrm{X}_{1}\right)$ & $-0.038 \mathrm{NS}$ \\
\hline 2. & Educational Level $\left(\mathrm{X}_{2}\right)$ & $-0.007 \mathrm{NS}$ \\
\hline $\mathbf{3 .}$ & Training Exposure $\left(\mathrm{X}_{3}\right)$ & $-0.303^{*}$ \\
\hline $\mathbf{4 .}$ & Service Experience $\left(\mathrm{X}_{4}\right)$ & $-0.038 \mathrm{NS}$ \\
\hline $\mathbf{5 .}$ & Attitude towards Agriculture Profession $\left(\mathrm{X}_{5}\right)$ & $0.417 * *$ \\
\hline $\mathbf{6 .}$ & Job Satisfaction $\left(\mathrm{X}_{6}\right)$ & $-0.109 \mathrm{NS}$ \\
\hline $\mathbf{7 .}$ & Information Seeking Behaviour $\left(\mathrm{X}_{7}\right)$ & $0.046 \mathrm{NS}$ \\
\hline $\mathbf{8 .}$ & Information Sharing Behaviour $\left(\mathrm{X}_{8}\right)$ & $0.109 \mathrm{~N}$ \\
\hline
\end{tabular}

**= Significant at 0.05 level of probability

***= Significant at 0.01 level of probability N S = Not Significant

In Horticulture assessment was done using twelve (12) perceived training needs and was reflected that "Methods of fruit and vegetable preservation including indigenous methods", with a score of 2.31 was the most needed and the 2 nd being, "Art of pruning, grafting and stalking", with a score of 2.27 and the 3rd, "Production technology of winter vegetables", with a score of 2.24 and lastly "Different equipment for pruning, grafting and spraying etc.", with a score of 2.18 .

In Entomology assessment was done using seventeen (17) perceived training needs, it was observed that respondents mostly needed training in, "Diagnostics and characteristic, symptoms and damage caused by insect pests", with score of 2.51 tied with "Symptoms, spread and control of important insect pests in rice", 2.51 .

This was followed with another tie of; "Insect pest management and its components (cultural, mechanical, biological, chemical and legal)", and "Identification of different pests and pesticides", both with scores of 2.49 .

In Plant Pathology assessment was done using sixteen (16) perceived training needs, it was observed that the respondents mostly needed training in; "Methods of application of chemicals, preparation and doses" with a score of 2.51, followed by, "Study of causes, symptoms, spread and control of important diseases in rice", with a score of 2.49 and the 3rd was, "Study of the causes, symptoms, spread and control of important diseases in vegetables", with a score of 2.40 .

In Nematology assessment was done using eight (8) perceived training needs and it showed that respondents most needed training in; "Nematode pest control in vegetables", with a score of 2.38 , the 2 nd was, "Nematode pest control in pulses", with score of 2.29, and the 3rd was, "Nematode pest control in cereals", with a score of 2.28 and lastly, "Important nematicide used in different crops", with a score of 2.27 .

In Agriculture Extension assessment was done using twenty-two (22) perceived training needs and it was revealed that respondents mostly needed training in "Promotion of rural youth activities", with a score of 2.60 , the 2 nd was, "Organisation of farm and farm women for agricultural production programmes," with a score of 2.58 and lastly the 4th was, "Extension Programme Planning and Monitoring at village level", with a score of 2.56 . 
In Agricultural Economics assessment was done using seven (7) perceived training needs which showed that respondents mostly needed training was, "Marketing of Agricultural products", with score of 2.58 ,the 2 nd was, "Sources of loan, knowledge of different credit institutions/agents" with a score of 2.49 ,the 3rd was "Farm management and economic production", with a score of 2.40 . "Seed production techniques" and "Drudgery reduction techniques", were also noted with scores of 2.33 and 2.24 respectively.

In conclusion the following findings relate to the objectives of there search and are clearly articulated in the following statements. Most of the respondents were found to be in the (36-55 years) middle age (75.60\%). It was also found that 53.30 per cent of the SMSs were M.Sc. Agriculture degree holders and 44.40 per cent were Ph.D. degree holders and 2.20 per cent were B.Sc. Agriculture degree holders.

The "Attitude towards the Agricultural Profession" was found to be favourable $(95.60 \%)$ of the respondents.

The "Service experiences", of the majority of the respondents was in the medium level category at $(64.50 \%)$ service experience in the range of (9 to 17) years. On "Training Exposure" of the majority were in the medium level category $(82.22 \%)$. The majority of the respondents were satisfied with their job (91.20\%). "Highly Satisfied" respondents and "Highly Dissatisfied" respondents were both at (4.40\%).

In the, "Information Seeking Behaviour" category, the majority of the respondents were in the medium level category $(57.80 \%)$. The high level category of "Information Seeking Behaviour" was 26.70 per cent and low level "Information Seeking Behaviour" was (15.50\%)of the respondents.
In the "Information Sharing behaviour", 57.80 per cent of the respondents were in the medium level 2.20 per cent were in the low level of "Information Sharing Behaviour" and high level of was $(40.00 \%)$.

On "Training Needs Scores," the majority of respondents were found to be in the medium level scoring $(73.40 \%)$. The low level score and high level score were both at (13.30\%).

From the results of the research a number of implications were recommended to the management of KVKs. The following are some of the recommendation and implications:

(a) The "Attitude towards Agriculture Profession" independent variable was found to be positively correlated with the training needs.

(b) (i) "Age" was found to have no significant relationship with the training needs. (ii) "Educational Level" was found to have no significant relationship with the training needs. (iii) "Service Experience" was found to have no significant relationship with the training needs. (iv) "Job Satisfaction" was found to have no significant relationship with the training needs (v) "Information Seeking Behaviour" was found to have no significant relationship with the training needs and lastly the (vi) "Information Sharing Behaviour" was found to have no correlation to the training needs.

(c)The "Training Exposure" was found to show a negative correlation to the training needs. The implication reflected by this was that, training needs of personnel in an organisation changes over time. Training needs assessment should be conducted in organisations periodically, to check who requires training and in which subject area.

(d)The research also showed critical areas where respondents needed training, these 
critical areas should be considered while planning for training, this research also showed that regardless of high educational qualifications the respondents had, gaps in knowledge and skills were exposed during the needs assessment and these should be checked regularly and addressed to improve their work performance.

(e) The "Training Needs" of most of the respondents were found to be in the medium level with 73.40 per cent representation. Basing on the aforementioned findings training programmes have to be planned on training needs basing on the needs of personnel, considering that new technology is coming into agriculture production systems.

(f) The training needs scores of the majority of respondents were found to be in the medium level score with 73.40 per cent. The low level score category was 13.30 per cent and 13.30 per cent were on high level score of training needs. More and more trainings will improve respondent's efficiency in executing their jobs.

(g) Most of the respondents were found to be in the Middle Age group. Considering the age category most of the KVKs had very active personnel which needed more motivation through training. The majority of the respondents were found to have high educational qualification with M.Sc. and Ph.D. Degree qualifications but however this did not portray high competence in the work performance hence training was still require.

(h) Most of the respondents reflected a favourable attitude towards the agriculture profession with $(95.6 \%)$. The favourable characteristic of the respondents to the profession is an advantage to management to achieve more of their organisational goals if some of the constraints identified in (Table 5) by the respondents were addressed.

(i) Further to the above assertion, management should take advantage of this high favourable attitude towards the profession perception and use some management human motivation theories for example, Douglas McGregor's Theory "Y" for SMSs to perform to their maximum. KVKs should give Incentives to SMSs for discovery of acceptable technologies and research discoveries that solve some of the farmers' current challenges.

(j) Management has to take advantage of the training needs the SMSs identified to come up with training programmes that will buttress the gaps in, knowledge and skills to improve their efficiency in disposal of their work.

(k) In relation to the eight disciplines that is Soil Science, Agronomy, Horticulture, Entomology, Plant Pathology, Nematology, Agricultural Extension and Agricultural Economics, the training needs of SMSs were found to be high in the following areas according to the rankings, "Soil conservation and its importance", "Knowledge of important varieties of Manipur", "Methods of fruit and vegetable preservation including indigenous methods", "Diagnostics and characteristic, symptoms and damage caused by insect pests", "Methods of application of chemicals, preparation and dozes", "Nematode pest control in vegetables", "Promotion of rural youth activities", "Marketing of Agricultural products".

(1) The trainings should prioritize key areas basing on the finding of this scientific research. Training need assessment allows employees to participate in deciding on areas to choose for training. This process creates a healthy working environment that improves on Quality of Work Life for organisational development.

(m) From the results of the investigation "Training exposure" was negatively correlated to the Training Needs, conclusions are that, the more someone gets exposed to training, the need to be trained decreases greatly. So when targeting SMSs for training, the KVK coordinators should consider the SMSs with lesser training scores and usually those newly employed and taking up new posts. 
(n) The current research was confined only to the SMSs but it could have been more prudent to capture more views, from all those who are working directly on transfer and refining of technology since the KVKs have more staff on the front line.

(p) For transfer, refinement and adoption of technology to happen, SMSs should undergo various trainings all the time so that they continue to be aware of advanced technologies that are currently being invented by various research institutions and universities which could be transferred for use by farmers to improve agriculture production.

(q) Someone who would want to carry out a follow up to this current research, there is needed to incorporate some more independent variables and more training need components like Fisheries, Food technology, Forestry and wildlife, Home science and Climate change could be included.

\section{References}

Deena, D., S.K., Devaran, L., Singh, R.J., and Feroze, S.M. (2019).Attitudes of agriculture collegian towards opting farming as a profession. Ind. J. Ext.Edu., 54 (3): 42-47.

Geetha, B. (2002). An analytic study on diversified farming in Chittoor district of Andhra Pradesh. Unpublished M.Sc. (Agri.) Thesis, Acharya N.G.Ranga Agricultural University, Hyderabad.

Jaganathan, D., Ram Bahal., Roy Buma, R., and Lenin, V. (2012). Knowledge level of farmers on organic farming in Tamil Nadu. Ind. Res. J.Ext.Edu., 12 (3): 70-73.
Kolawole, E.A., Isitor, S.U. and Owolabi, A.O. (2016).Determinants of training needs of extension personnel of Agricultural Development Programme (ADP) Ekiti State Nigeria. Agro-Sci. J. of Tropical Agric., Food, Environ. Ext Edu., 15 (3):13-17.

Mohammed, S.J., Norsida, B.M., Garba, M.B., Al-Lahibi Z. FalahHasan., and Mohammed, S.J. (2017). Analysis of training needs to improve job performance Using the Borich need Assessment with Theory of SelfEfficacy. Asian Research J. Agric., 3 (3): $1-16$.

Mohan, B. (2000). A study on job performance and satisfaction of assistant agricultural officers in the Northern district of Karnataka MSc. Thesis, Submitted to the University of Agricultural Sciences, Dharwad.

Nanda, H., Chandra, S., and Kaur, A.P. (1994). Training needs of farm women in potato growing. J. Ind. Potato Assn., 21 (1\&2): 133-137.

Sarker, N.I., Sultana, A., and Prodhun, S. (2017). Job satisfaction of public and private organisations in Bangladesh. Journal of Political Science, Public and International Affairs., 1 (1): 02-08.

Sultana, A. (2016). Information seeking behaviour of academics of Maulana, Azad national Urdu University in the digital environment. In S. Dhanavandan, Transition in Librarianship (pp.245-252) Delhi: Diminant Publishers and Distribution Pvt. Ltd.

Udoh, A.J. and Umoh, C.E. (2011).Utilization pattern of pesticides by Nigerian farm households. Ind. Res. J. Ext. Edu., 11 (2).

\section{How to cite this article:}

Mhike Augustine, M. Devi Deepa, A. Prasad and Nath, D. 2020. The Study of Training Needs Assessment of Subject Matter Specialists of the KVKS of the State of Manipur, India. Int.J.Curr.Microbiol.App.Sci. 9(08): 3755-3767. doi: https://doi.org/10.20546/ijcmas.2020.908.434 